\title{
How does FDAC succeed with parents with substance misuse problems? Exploring relational practices within the English Family Drug Alcohol Court
}

\begin{abstract}
Parental substance misuse is a significant risk factor for child maltreatment and is frequently involved in care proceedings. Outcomes are often poor and family reunification is prone to breakdown. In this article the contribution of the English Family Drug and Alcohol Court (FDAC), is examined. Adapted from the American family drug treatment court model, FDAC offers a radically different approach to ordinary care proceedings by treating parents as well as adjudicating. The article draws on a mixed methods evaluation of FDAC which reports better recovery and reunification rates than ordinary court. It presents findings from 42 parent interviews and 154 court observations of 89 cases, focusing on FDAC's relational practices. The article concludes that these relational practices offer hope to substance misusing parents and that the approach merits wider attention because of its therapeutic potential and distinctive approach to justice.
\end{abstract}

\section{Key words}

Family drug treatment courts; relational practice; child maltreatment; substance misuse

\section{Practice messages}

- $\quad$ FDAC is a helpful approach to care proceedings for substance misusing parents.

- Parents value clear, consistent and honest messages about their progress when delivered in the context of trusted relationships and intensive support.

- Parents need holistic help that takes into account damaging early life experiences. 


\section{Manuscript}

\section{Introduction}

Parental substance misuse is a major reason internationally for child maltreatment and court-mandated permanent removal of the child from birth parents. This evidence has been a major catalyst to the growth of family drug treatment courts which first developed in the US and have spread to England, (where they are called Family Drug and Alcohol Courts [FDACs]), with pilot courts in Australia and Northern Ireland. Underpinned by principles of therapeutic jurisprudence, family drug treatment courts combine therapeutic treatment with adjudication in the belief that change cannot be achieved without addressing underlying problems within the court process. Crucially the court itself is seen as an agent of change, rather than a place of last resort.

American evidence consistently reports higher rates of substance misuse cessation and family reunification and lower spending on out of home placements in family drug treatment courts (FDTCs) compared to ordinary court and service delivery (Worcel et al., 2007; Lloyd, 2015). A mixed methods evaluation of the London FDAC also found that compared to cases heard in ordinary court, it achieved higher rates of family reunification and substance misuse cessation at the end of the proceedings (Harwin et al., 2014). These outcomes were more likely to be sustained up to five years after the FDAC intervention and court process ended (Harwin et al., 2016).

The American evidence also suggests that FDTCs are valued by clients for the emotional and practical support they provide, the collaborative approach with "clear lines of mutual responsibility' and 'the sense of accomplishment', with the role of the judge singled out for special praise (Worcel et al., 2007). However, the published qualitative evidence is limited 
(Lloyd, 2015) and no published studies have used systematic court observations to explore how far family drug courts achieve the problem-solving approach they aspire to.

This article aims to contribute to the international evidence and help address these gaps. It presents findings from court observations and parent interviews carried out as part of the mixed methods evaluation of FDAC to examine how far it delivers distinctive practices that demonstrate adherence to the model of problem-solving courts. It argues that these practices are in line with relational theory and practice, an approach which is particularly suited to working with parents who are hard to help.

The article first considers why parents can be hard to help before outlining how FDAC operates so as to promote effective relational practices.

\section{Understanding why parents can be hard to help}

A body of knowledge helps explain why some parents are hard to help and suggests that far greater attention be paid to the relational aspects of practice (Ruch \& Julkenen, 2016). Parents who appear as respondents in care proceedings typically have experienced childhood neglect and maltreatment themselves, as was the case for many parents in the FDAC and comparison cohorts (Harwin et al., 2014, 2016). Trust is a critical issue for this population of parents which impacts on their ability to receive help because of unhelpful belief systems and fundamental problems of feeling safe or secure in the world. (Van der Kolk et al., 2005; Anda et al., 2006; Briere et al., 2008).

Parents who misuse substances raise additional complexities and challenges to building trusting relationships that can promote change. Drug and alcohol misuse are powerful habits which provide subjective rewards both psychologically and physiologically (Orford, 2013) but result in loss of personal agency. Parental needs can take precedence over all others, including their child's wellbeing (Forrester \& Harwin, 2011). Compounding complications are that misuse of street drugs is a criminal offence and social attitudes towards mothers who misuse substances are frequently stigmatising (Orford, 2013) while stereotypes of substance 
misusing fathers present them as at best, 'uninvolved and irrelevant' and at worst, 'potentially dangerous' (McMahon \& Giannini, 2003, p.339). All these factors help explain why resistance is such a common phenomenon in treating substance misuse (Forrester et al., 2012). Professionals are unlikely to succeed in helping parents to change when they do not recognize the ways in which problem behaviours are 'functional' for these parents or understand the specific gender related issues (McMahon \& Giannini, 2003). Issuing care proceedings will most likely trigger or exacerbate maladaptive coping mechanisms, compound unhelpful belief systems and potentially alienate parents further from informal and formal helping networks.

The complex presentation of enduring difficulties requires highly skilled and sensitive work to engage parents. Evidence from the research literature is that the following qualities of the helping relationship are critical to breaking through resistance and fostering trust: consistency, acknowledgement of disadvantage and trauma, valuing of strengths and a collaborative approach to helping (Rosenberger, 2013; Folgheraiter, 2007). Long-standing evidence shows that honesty and respect are prized by families (Forrester \& Harwin, 2011).

Relational theory and practice potentially holds out promise to this group of highly marginalised and alienated parents with its emphasis on 'relational parity rather than hierarchy', 'co-construction of meaning', use of a strengths-based approach rather than a deficit model, and its recognition of the important role of social networks as mediators of change (Rosenberger, 2013, Folgheraiter, 2007). However relational theorists have also noted that partnership and participation can be particularly challenging in child protection, weakening prospects for empowerment (Folgheraitier, 2007).

The problem-solving court approach used in FDAC, as already noted, is underpinned by the principles of therapeutic jurisprudence (Winick \& Wexler, 2001; Winick, 2002; Kaiser \& Holtfreter, 2016). These principles are in line with the relational theory and practice outlined above (Lloyd, 2015) and they draw extensively on motivational psychology and strengths- 
based approaches to promote change. Based on the 'right to a second chance' and 'recognition of the personal dignity of all persons' (Honneth, 2001), therapeutic jurisprudence seeks to instil an ethos of hope within the limited timeframe of proceedings. It also asserts that respect for the law is enhanced if the judicial process is perceived to be fair by respondents. For this reason, the process seeks to be participatory and to encourage the voice of the parent to be heard in court. The approach is intended to be collaborative rather than adversarial because treatment often requires the involvement of several agencies and because an adversarial approach fosters hostility rather than constructive solutions. In FDAC this results in seeking to practise relational principles within the framework of care proceedings, despite the challenges to partnership and participation.

\section{FDAC: creating the conditions for effective relational practices}

FDAC's main features are a specially trained judge and a multi-disciplinary, specialist team working closely together. The aim is for the judge and team to build a relationship with the parents to help motivate them to change. The specialist team, which is independent of the local authority bringing the proceedings, advises the court, provides intensive treatment and support to parents and co-ordinates other agencies working with the family. The same judge hears the case throughout and uses regular fortnightly court reviews without lawyers present as the forum for engaging parents in tackling the problems that put their children at risk of harm. These reviews are attended by the judge, the parents, the FDAC key workers and local authority social worker, and the children's guardian. In ordinary care proceedings there is no multidisciplinary team and no judge-led review hearings without lawyers. Parents do not engage in conversation with the judge.

The non-lawyer review hearings and multidisciplinary team create the structures and framework for promoting consistent, dependable and trusting relationships between judge and parent, and specialist team and parent within the proceedings. The specialist team helps 
ensure that skilled help is available to tackle holistically the full range of problems that parents experience.

\section{Context and setting}

The London FDAC was set up in 2008 and was the first such court in the UK. The evaluation was commissioned to provide evidence for policy-makers and service planners as to whether FDAC offered a better approach to the widespread problem of parental substance misuse in care proceedings than ordinary court and services. It was funded in two stages (2008-2010) and 2010-2014 by the Nuffield Foundation.

The study took place in Central London at the Inner London Family Proceedings Court, the FDAC team office, and in 3 London pilot authorities and 3 comparison authorities. In 2016 the research also included court locations in the North, Midlands, South East and South West of England, and in both urban and rural settings.

\section{Methodology}

\section{Court observations}

114 court observations of the London FDAC were carried out concerning 49 cases heard in 2009, 2011 and 2013, comprising 54\% of the total FDAC cohort of 90 families. Selection criteria were that the observations included cases heard by the two main London FDAC judges and the two back-up judges, and cases brought by all three pilot local authorities. A further criterion was that hearings were observed at the start, middle and end of the case and with, and without lawyers present.

In 2009 when the London FDAC was still a very young service, priority was given to in-depth tracking of 7 cases in which at least 7 hearings had been observed per case. A similar approach was adopted in the observations of 7 further cases in 2011 where the aim was to see if there had been any changes in judicial behaviour over time. The analysis covered 5 hearings per case, and included the first and second court hearing, first, second and seventh 
review hearing. This range shed light on judicial interaction with parents as the case developed, with and without lawyers present. The third set of observations in 2013 focused specifically on later review hearings to capture interactions between parents and judges.

The cases in the London FDAC provided a cross-selection of relevant features. They cases concerned mothers alone, others with fathers who were party to the proceedings, cases involving new born babies and older childen, and those where children were living at home with their mothers and others were they were with relatives or in foster care. Substance misuse profiles included drug and alcohol misuse, drugs alone and alcohol alone. The cases included reunification and others where the children were placed with alternative families.

The 2016 observations of 40 cases included hearings from the London FDAC but the majority were in courts out of London. Three had been running for more than one year and 6 courts had been operating for several months only. Both male and female judges were observed. All had experience of adjudicating in ordinary care proceedings. The researchers had no prior knowledge of the cases.

Measurement: a semi-structured observation schedule was devised based on judicial behaviours that had been identified from research into family drug treatment courts in the US. The questions were about the extent to which the judges succeeded in: talking to parents; inviting their views; expressing interest in their progress; acknowledging family strengths; offering praise to parents; explaining the aims of FDAC; explaining decisions made; urging parents to take responsibility for their actions, and using time in court to tackle the range of problems faced by parents (this last question was only included in 2013 and 2016).

Procedure: researchers sat in court and took contemporaneous notes, recording verbatim exemplars of the themes. For each case, basic (anonymised) details were recorded, summarising the issues, the people present, and the type and length of hearing. 
Data analysis: the data were analysed by two researchers independently. For the quantitative analysis, a simple count was kept of whether the judge had provided at least one example to evidence each of the 9 problem solving practices. For the qualitative analysis, the themes were triangulated with those from the parent interviews to explore adherence to the problem-solving model.

Permissions to carry out the court observations were received from Her Majesty's Courts and Tribunal Service, and Designated Family Judges. Parents and other parties to the proceedings were asked whether they consented to observations of the hearing.

Parent interviews: these were designed to canvass parental views and experiences of FDAC, chart their perceptions of the support they received, and their own part in bringing about change, and to see if they had any recommendations about FDAC and its value for other parents in similar situations.

Measurement: a semi-structured questionnaire was devised to explore the above themes, informed by the parental schedule used in the national US evaluation of family drug treatment courts. All interviews were taped, transcribed and analysed to examine whether they described distinctive practices that were in line with the problem-solving model and with relational practice.

Procedure: all parents were invited to take part in an interview. A condition was that they took place after parents had signed up for FDAC to avoid risk of researcher influence on the decision to join the programme. Interviews were held at different stages in the court process and were carried out face to face and over the telephone. Parents were offered a voucher in recognition of their time and help. The interviews were conducted between $2009-2013$.

Ethical approval was obtained from Brunel University London and the court to carry out the interviews.

\section{Results}




\section{Were judges implementing relational practices in line with problem-solving practice? Findings from the court observations}

Figure 1 summarises the extent to which the judges were implementing problem-solving on the nine measures. Despite some fluctuations, the highest scores were found for measures 1,2 , and 9 , while scores increased over time for most other measures. It is not clear why cases observed in 2011 consistently had lower scores.

\section{Figure 1 here}

The context for each of the practices that were observed may help explain some of the variation. While it might have been expected that measures $1-3,5$ and 9 would be observed in all hearings, the findings suggest that this was not automatically so for other measures and this may contribute to the lower scores. Explaining the aims of FDAC was less likely to be relevant for hearings observed later in the case while scores on family strengths depended on whether a relative was in court. Urging parents to take responsibility was essential when the case was running into difficulties but otherwise there was greater leeway. It was also anticipated that there would be less direct communication with parents in hearings where lawyers were present.

The summary percentages convey little of the way in which the judges engaged with parents, sought to empower them, and remind them of their responsibilities. They were strikingly consistent in the words they used to explain the aims of FDAC, often interspersed with questions to gauge whether parents had a grasp of what was happening, and to engage them in the court and FDAC process.

'Can you tell me what the object of FDAC is? ... It's to help you provide the best possible parenting for your baby. It doesn't always work but we want to try it with you.' 
'You sign, I sign and FDAC signs. This means you know you've got problems and we're all going to work on them.'

'I am glad that you have decided to sign up to FDAC. We are going to try and work together and achieve the aim of the children staying with you, because that is what we all want. It will be intensive and I don't want you to quit.'

As the above examples demonstrate, by the frequent use of 'we', the judges emphasized that the approach was collaborative but also personalised their relationship with the parent-'I don't want you to quit'.

The judges sought to maintain engagement by regularly expressing interest in parental progress. Even when they had something of concern to discuss with parents, their opening comments were welcoming and friendly. They expressed interest in understanding what parents were worrying about, probing for explanations and encouraging parents to bring problems into the open. The examples below illustrate these points:

'How are you doing? I hear there's good news on the job front. But there's been another incident. Let's talk about that.'

'Why is it that you don't attend regularly? What is getting in the way of you going? Can you help me understand that?'

Praise was part of the armoury of the judges and it became more systematically embedded as a judicial practice over time. It was used both to reinforce good progress but also to find positives when plans were not succeeding and this helps explain why the percentages on this measure were high. The examples below illustrate both these points.

'Your child is a great credit to you both. You deserve a medal for the changes you have made to your life.' 
'A lot of mothers would have stormed out of a meeting when told their child was not coming home, especially when some things have gone so well. So it was very brave of you to stay and talk. I know how well you've done and I think that's very important. Tell me how [child] was last week.'

Praise was one side of the coin. The other was if judges were able to strike the balance between encouragement and challenge when progress was not sufficient or quick enough, to meet the child's needs. This is what was meant by urging parents to take responsibility. To some extent, as noted above, this issue was case dependent, and it may not have been relevant at a given hearing. Nevertheless, there were many examples to capture how the judges conveyed difficult messages. The consequences of non-compliance were spelt out and when possible, with empathy and encouragement to learn from past mistakes and thereby retain an ethos of hope. Parents were challenged, but without confrontation.

'This is the time to focus 100 per cent on your treatment ... your frustration [over contact] is understandable, but don't be deflected ... it's up to you at the end of the day.'

'The important thing is that you have been honest about your lapse ... you will always have moments that are difficult ... the evidence is that you are asking for help and wanting to make changes. Keep doing that.'

'Life is hard and being a parent one of the hardest things. Often in life it's not about being perfect but about trying very hard to get it right. You know your child best and what they like and how to make things better and what to steer away from. Hold these things in mind.'

As already noted, evidence of problem-solving was found in all hearings. This practice was as much about working collaboratively with other professions as well as with the parents. Judges identified issues for discussion and steered conversations to finding practical solutions, such as for help in accessing counselling, suitable housing, and help with travel costs. 
'Before the next review in two weeks, l'd really like to see the FDAC team, the guardian and the local authority meet with the father and see if they can agree a placement package, and bring the children into that discussion. Could you do that?'

'If the decision is for you and baby to move from residential to community housing, the local authority have to think creatively about where to house you. I flagged this up at the last hearing and they might have to come back and explain where they have got to.'

Overall the court observations suggest that the judges were implementing problem-solving practice with improvements over time. This was so in the newest courts as well as in London, suggesting that the approach is replicable (Tunnard et al., 2016).

\section{The experience of FDAC: findings from the interviews with parents}

A total of 42 interviews were carried out concerning 32 cases. 31 interviews were with mothers and 11 with fathers. The profile of this sub-set of families was broadly similar to that of the overall FDAC cohort in most ways. The majority of cases involved only one child $(69 \%$ $\vee 71 \%)$ and were headed by a lone mother (66\% v 56\%). The largest group of mothers were aged between 30-39 (66\% v 59\%) and were White British, Irish or other (76\% v 76\%). A history of being looked after once or more was common (28\% v $31 \%)$ as was the experience of having children removed in previous proceedings ( $48 \% \vee 41 \%)$. The profiles of maternal substance misuse were also similar. The most frequent pattern was misuse of both drugs and alcohol (45\% v 44\%), followed by drugs only (34\% v 38\%) and alcohol only ( $21 \% \vee$ $18 \%)$. The percentage of mothers with mental illness at the start of the case was similar $(38 \% \vee 34 \%)$ as was a history of mental illness (55\% v 52\%). A history of domestic abuse affected a smaller proportion of the mothers who were interviewed than the total sample ( $41 \%$ v $80 \%)$. There was one important way in which the cases differed from the overall cohort. A higher proportion of the families interviewed (59\% v 35\%) were reunited with their children at the end of the case. File data recorded on the fathers was too patchy to present. 
The main message from parents was that FDAC is a service they would recommend to others. Those with previous experiences of care proceedings felt that it provided a more helpful process. They recalled how previously they had felt like 'junkies' or 'prostitutes' and that 'it was a losing battle' because the court 'just took children away from you'. By contrast, FDAC 'is much more intimate, more supportive'. All but two parents felt that FDAC gave them a fair chance to change their lifestyle and to turn their life around. One parent felt that she would have been successful without FDAC and the other said that a different process would make no difference to her.

Strong views emerged from parental accounts on the importance of the judge. They suggest that he was perceived as a powerful lever for change. Judges were described as the 'man with the final word', and 'king' with the power to 'overrule the local authority' and ability to 'look at both sides' and 'see the good side of families'. (All the judges at the time of the interviews were male). The word 'fair' was the most frequent attribute ascribed to judges and parents valued this even when they did not like what the judge had to say to them.

'If you engage and you do things right, he's very understanding and won't judge you and doesn't treat you differently. But if you mess about and you aren't committed, he will come down on you. So he's very fair'.

'At first I didn't like him because he was honest. He was saying it how it was and it was bad. It was horrible. But now I know it was the truth'.

The personal attributes of the judge were also highly valued. They helped diffuse the anxiety of coming to court because they 'treated you like a human being', 'talked about normal things' and 'put you at your ease'. They were 'reasonable', 'funny', 'encouraging', 'sensitive' and 'calm' and 'knowledgeable about your case'.

Winning judicial praise motivated parents more than from any other professional. Praise from parents' lawyers was either 'expected' or 'not the same' and when it came from social workers it was perceived as 'just a little muttering under her breath or 'never said in a way 
that feels nice'. When praise came from the judge, in the words of one parent, 'I come out feeling really happy'.

Although parental testimony was consistently favourable about the judges, not all parents found it possible to be open and honest with them. Sometimes it was because they wanted to please the judge and feared his censure if their progress faltered. At other times parents thought that they might harm their case if they openly expressed their views, especially when they had criticisms of the local authority. The examples below demonstrate the barriers to achieving trusting relationships with the court.

'I feel like I can't say ...I've been having a couple of bad days because he's a judge and he's so powerful so l'd rather talk to [my FDAC keyworker].'

'It's not the court or the FDAC team that puts me off speaking my mind, it's the local authority'.

The FDAC team was also praised by parents and seen as a crucial source of practical and emotional support. Parents used terms such as 'helpful', 'supportive', 'life-changing' and 'fantastic' to describe the team. They appreciated 'being talked to as normal' and 'not being judged straight away'. FDAC 'listened' and 'were always explaining things'. They valued team members being 'strict', 'not a soft touch', and their ability to 'say things that perhaps you don't want to hear' alongside being 'honest', 'supportive' and 'kind'. Parents said these qualities helped them discuss problems openly and realistically and retain hope.

'Instead of fibbing we're encouraged to be honest and if we relapse, or lapse even, we're told it wouldn't be the end of it, because they would work with us about that. They were being honest with us and making it easier for us to be honest with them.'

The support provided by the team varied for each parent but several common themes emerged. They included helping bring back order into their lives, explaining the legal process clearly, carrying out swift assessments, and linking them to community services. 
'When I got introduced to FDAC it was like they were my diary and they were telling me where I had to be. They were my rock and my support'.

'The support they give me is amazing. It can be about anything that's worrying me or getting me down. It's not just about drugs and it can be really, really silly and they'll still listen and help'.

'I have meetings during the week to prepare for court. I see my key worker at FDAC and he always asks me whether there is anything particular I want to go over. And I can see what he's written.'

Parents were able to explain their substance misuse treatment goals clearly and most agreed with them, but views were more mixed on receiving parenting support. A few parents, especially those interviewed in the early days of FDAC, did not see parenting support as a key part of the intervention. Others thought they were already good-enough parents. Even those who valued FDAC's help in parenting, acknowledged the sensitivity of this subject.

'It's the most degrading thing if people say they are worried about your children. No harm ever came to him, so why pick on us. I still feel that a bit but I know things weren't right...but that was just 'addict thinking'. Things are totally different now. And the children are appreciative of me being a dad to them'.

Overall, however, the help that parents felt they had received from FDAC was reflected in their wish to stay in touch with FDAC after their case in court had ended. They saw this as a source of support and encouragement as well as preventing relapse and helping facilitate access to education, employment, benefits and housing advice. But they understood that the role was time-limited and could not be imposed on a parent.

'I'd like FDAC to stay on after the case finishes...l've built up such a strong bond with my keyworker that I feel I could talk to him about any concerns I've got. I haven't got that feeling with anyone else'. 
The experience of FDAC also helped parents improve their relationship with other professionals, notably the children's social workers. They came to understand that they were 'not just there to pick on me... but are there for the safety of the children'. This was important because parents reunited with their children looked to children's services to provide support after the proceedings ended.

The perception of fairness not only meant a less adversarial approach but was acknowledged by parents as helping them understand if the final decision by the judge was that their children could not return to their care:

'It's always nice to be given a chance. If you then mess up you can never say you weren't helped and given that chance.'

\section{Discussion}

One of the most important questions raised by FDTCs is why they deliver better recovery and reunification outcomes at the end of the court process. Unlike the US adult criminal drug courts, (Rossman et al. 2011), no largescale studies have investigated empirically the relative importance of the qualitative components of family FDTCs. Nevertheless, the limited US evidence suggests that they are better able to build on the potential of parents than ordinary courts and services and that the better outcomes are likely to be linked to the relational practices as well as the court process.

The English findings reported in this article provide further support for this view. They have shown that courts do carry out problem-solving practice in well-established and newer courts in different parts of the country, with different judges, whether male or female. They have also confirmed that the majority of parents would recommend FDAC. Their accounts suggest that the relational practices by judges and the FDAC team were important contributory factors. 
In understanding the reasons for parents' overall endorsement, key themes to emerge were the ability of FDAC to make parents feel valued, supported, not stigmatised, able to share their difficulties, understand the court process, and see it as fair. These features contrast with findings on parental perspectives in ordinary care proceedings, which highlight lack of understanding of the process, alienation and lowering of self-esteem (Hunt, 2010; Broadhurst et al., 2017). The importance of the judges resonates with the American evidence in both FDTCs and criminal adult drug courts. One theory is that 'this is the first time that a powerful person has shown an interest in their [parent] well-being' (Edwards \& Ray, 2005). Perceptions of fairness, demonstrated so clearly in this study, are also in line with the qualitative literature on FDTCs and adult drug courts (Rossman et al., 2011) which suggest that 'fairness' is associated with reduced crime rates.

The qualities that parents valued in the FDAC team also align well with the international literature on working with parents who are hard to help -availability, dependability, practical solutions, and understanding of historic adversity. In FDAC the structures that promoted these consistent and dependable relational practices were the non-lawyer reviews hearing and the specialist team with regular meetings with keyworkers.

However, the relational practices did not work for all parents and notably, some parents found it difficult to be open and honest and to acknowledge parenting difficulties. It underlines the point that recovery is a complex process and that many factors affect treatment readiness (Best et al., 2015). It was therefore disappointing not to be able to interview parents who disengaged. Obtaining their perspectives would enrich understanding of barriers and potentially hold out useful messages for FDAC and family drug treatment courts more generally to increase their success rates. This would be a fruitful line of further research. Obtaining parental testimony following the introduction of the Children and Families Act 2014 and shorter court timescales to achieve change would also be particularly valuable in light of evidence of the challenges in building and sustaining relationships with substance misusing parents in care proceedings. 


\section{Limitations of the study}

The sub-set of parents who were interviewed was more likely to be reunited with their children than the total cohort and it was not possible to interview parents who refused the offer of FDAC or who had dropped out of the process despite efforts to do so. The findings are therefore not representative of the full spectrum of parents for whom FDAC was recommended or accessed and it is possible that the views reported here were more positive than would have otherwise been the case. The study was only funded to interview FDAC parents so no comparisons can be drawn with the views of parents in ordinary proceedings.

The court observations also had some limitations. Although the hearings covered a spectrum of cases and judges, it cannot be assumed that the hearings were fully representative of all hearings. Provided that these points are recognised, the findings allow the study to draw some valuable conclusions.

\section{Conclusions}

FDTCs represent a paradigm shift. These courts assert that by skilled assessment and intensive therapeutic relationships it is possible to help overcome deep-seated patterns of mistrust and destructive entrenched patterns of behaviour that are so widespread amongst parents who misuse drugs and alcohol and are brought before the courts because of the significant harm they are causing their children. The qualitative findings from this study, when combined with the evidence of better parental and child outcomes, provides support for the model and for further probing of the mechanisms by which it can bring about constructive and enduring change. The findings reinforce the importance of effective relational practices. What is distinctive about FDTCs is that these practices take place within the court arena. 


\section{References}

- $\quad$ Anda, R.F. Felitti, V.J. Bremner, J.D. Walker, J.D. Whitfield, C.H. Perry, B.D. Dube, S.R. and Giles, W.H. 2006. The enduring effects of abuse andrelated adverse experiences in childhood. European archives of psychiatry and clinical neuroscience, 256(3), pp.174-186.

- Best, D., Albertson, K., Irving, J., Lightowlers, C., Mama-Rudd, A., \& Chaggar, A. (2015). The UK Life in Recovery Survey 2015: the first national UK survey of addiction recovery experiences. Retrieved $24^{\text {th }}$ January 2018 from http://shura.shu.ac.uk/12200/

- Brandon, M. Bailey, S. and Belderson, P. 2010. Building on the learning from serious case reviews: a two-year analysis of child protection database notifications 20072009. Department for Education (DFE)

- $\quad$ Briere, J. Kaltman, S. and Green, B.L. 2008. Accumulated childhood trauma and symptom complexity. Journal of traumatic stress, 21(2), pp.223-226.

- Broadhurst, K. Mason, C. Bedston, S. Alrouh, B. Morriss, L. McQuarrie. T. Palmer. M. Shaw, M. Harwin, J. \& Kershaw, S., 2017. Vulnerable Birth Mothers and Recurrent Care Proceedings, Lancaster University.

- $\quad$ Edwards, J.L.P. and Ray, J.J.A., 2005. Judicial perspectives on family drug treatment courts. Juvenile and Family Court Journal, 56(3), pp.1-27.

- Felitti V.J. \& Anda R.F. 2010.The Relationship of Adverse Childhood Experiences to Adult Health, Well-being, Social Function, and Healthcare: in R Lanius, E Vermetten \& C Pain. The Impact of Early Life Trauma on Health and Disease the Hidden Epidemic. Cambridge University Press

- Folgheraiter, F. 2007. Relational Social Work: Principles and Practices. Social Policy and Society, 6(2), 265-274. doi:10.1017/S1474746406003526

- Forrester, D. and Harwin, J. 2011. Parents who misuse drugs and alcohol: Effective interventions in social work and child protection (Vol. 30). John Wiley \& Sons. 
- Forrester, D., Westlake, D. and Glynn, G. (2012), Parental resistance and social worker skills: towards a theory of motivational social work. Child \& Family Social Work, 17: 118-129. doi:10.1111/j.1365-2206.2012.00837.x

- Green, B.L., Furrer, C., Worcel, S., Burrus, S. and Finigan, M.W., 2007. How effective are family treatment drug courts? Outcomes from a four-site national study. Child Maltreatment, 12(1), pp.43-59.

- Harwin, J. and Ryan, M. 2008. The role of the court in cases concerning parental substance misuse and children at risk of harm. Journal of Social Welfare \& Family Law, 29(3-4), pp.277-292.

- Harwin, J., Alrouh, B., Ryan, M. and Tunnard, J., 2013. Strengthening prospects for safe and lasting family reunification: can a Family Drug and Alcohol Court make a contribution? Journal of Social Welfare and Family Law, 35(4), pp.459-474.

- Harwin, J Alrouh, B., Ryan, M. and Tunnard, J., 2014. Changing Lifestyles, Keeping Children Safe: an evaluation of the first Family Drug and Alcohol Court (FDAC) in care proceedings. Brunel University.

- Harwin, J. Alrouh, B. Ryan, M. McQuarrie, T. Golding, L. Broadhurst, K. Tunnard, J and Swift, S, 2016. After FDAC: outcomes 5 years later, Final Report, Lancaster University.

- Harwin J, Ryan, M. and Kershaw, S (forthcoming 2018) The Family Drug and Alcohol Court: a problem solving approach to family justice in Shaw, M and Bailey, S (eds). Family Justice: a developmental perspective. Cambridge University Press

- Honneth, A. 2001. Recognition or redistribution? Theory, Culture \& Society, 18(2-3), pp.43-55.

- Hunt, J., 2010. Parental perspectives on the family justice system in England and Wales: a review of research. Nuffield Foundation.

- Kaiser, K.A. and Holtfreter, K. (2016) An Integrated Theory of Specialized Court Programs: Using Procedural Justice and Therapeutic Jurisprudence to Promote 
Offender Compliance and Rehabilitation, Criminal Justice and Behavior. Vol. 43 (1), 45-62 https://doi.org/10.1177/0093854815609642

- Lindley, B. 1994. On the Receiving End: Families' Experiences of the Court Process in Care and Supervision Proceedings Under the Children Act 1989. London: Family Rights Group.

- $\quad$ Lloyd, M. 2015. Family drug courts: Conceptual frameworks, empirical evidence, and implications for social work. Families in Society: The Journal of Contemporary Social Services, 96(1), pp.49-57.

- Masson, J. M. Pearce, J. F. \& Bader, K. F. (2008). Care Profiling Study (Ministry of Justice Research Series 4/08). (Ministry of Justice Research Report; Vol. 08, No. 4). Ministry of Justice and Department of Children, Schools and Families.

- McMahon, T.J. and Giannini, F.D., 2003. Substance-Abusing Fathers in Family Court. Family Court Review, 41(3), pp.337-353.

- Orford, J. 2013. Power, Powerlessness and Addiction. Cambridge. Cambridge University Press

- Pearce, J. Masson, J.M. and Bader, K. 2011. Just Following Instructions?: The Representation of Parents in Care Proceedings: Report of ESRC, RES-062-23-1163. School of Law, University of Bristol.

- Rossman, S.B. Roman, J.K. Zweig, J.M., Rempel, M. and Lindquist, C.H. 2011. The multi-site adult drug court evaluation: The impact of drug courts.

- $\quad$ Rosenberger, J.B. (ed) (2013) Relational social work practice with diverse populations. New York, NY.

- Ruch, G. and Julkenen, I, (eds). (2016) Relationship-based research in social work: understanding practice research. Jessica Kingsley, London. ISBN 9781849054577

- $\quad$ Tyler, T.R., and Lind, A.E. (1992) A relational model of authority in groups, Advances in experimental social psychology 25, 115-92. 
- Tunnard, J. Ryan, M and Harwin, J. 2016. Problem Solving in Court: Current Practice in FDACs in England, Final Report (December 2016), Lancaster University

- $\quad$ Van der Kolk, B.A. Roth, S. Pelcovitz, D. Sunday, S. and Spinazzola, J. 2005.

Disorders of extreme stress: The empirical foundation of a complex adaptation to trauma. Journal of traumatic stress, 18(5), pp.389-399.

- Winick, B.J. and Wexler, D.B. 2001. Drug treatment court: Therapeutic jurisprudence applied. Touro L. Rev., 18, p.479.

- Winick, B.J. 2002. Therapeutic jurisprudence and problem solving courts. Fordham Urb. LJ, 30, p.1055.

- Worcel, S.D. Green, B.L. Furrer, C.J. Burrus, S.W. and Finigan, M.W. 2007. Family treatment drug court evaluation: Final report. Portland, OR: NPC Research. 